\title{
DENSITY AND RADIOLYTIC DECOMPOSITION OF PLUTONIUM NITRATE SOLUTIONS
}

\author{
Arturo Maimoni
}

\section{MASTER}

October 1979

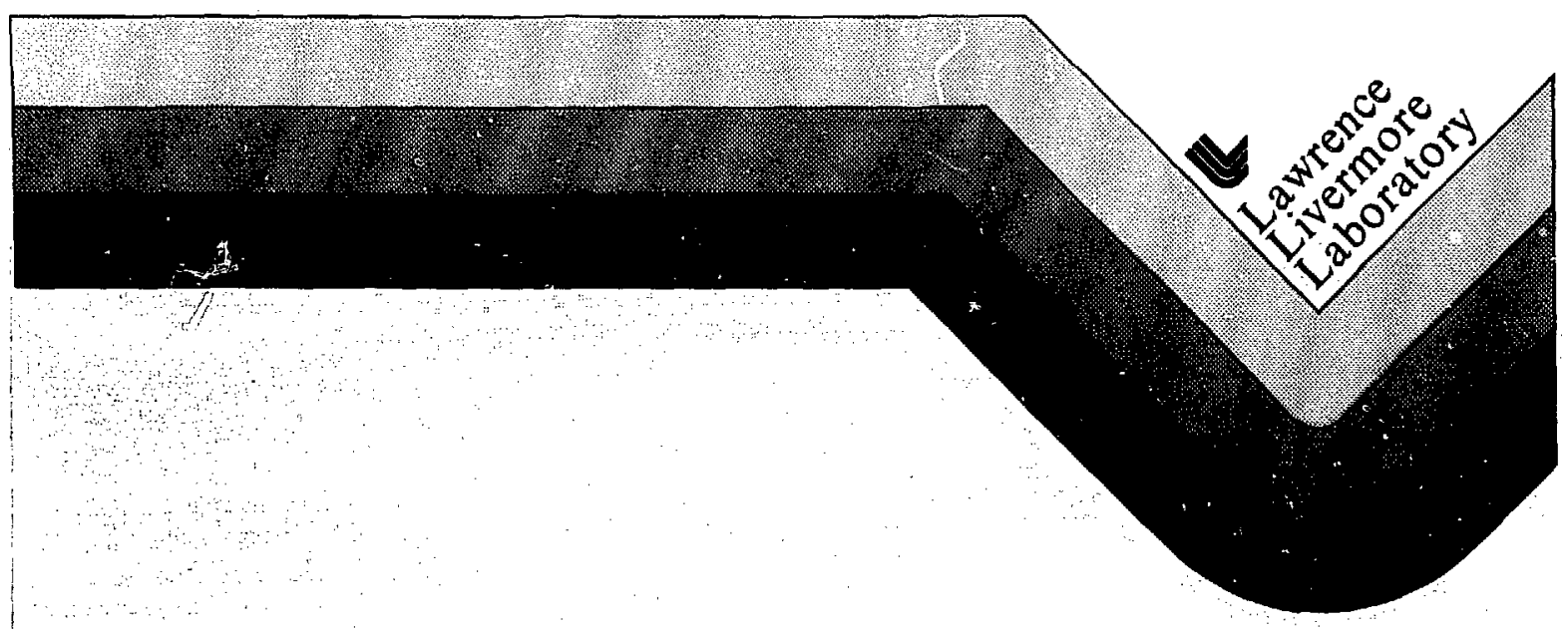




\title{
DENSITY AND RADIOLYTIC DECOMPOSITION OF PLUTONIUM NITRATE SOLUTIONS
}

\author{
Arturo Maimoni \\ Manuscript date: October 1979

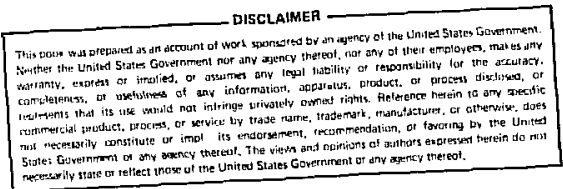

LAWRENCE LIVERMORE LABORATORY University of California - Livermore, California $\cdot 94550$ 


\section{CONTENTS}

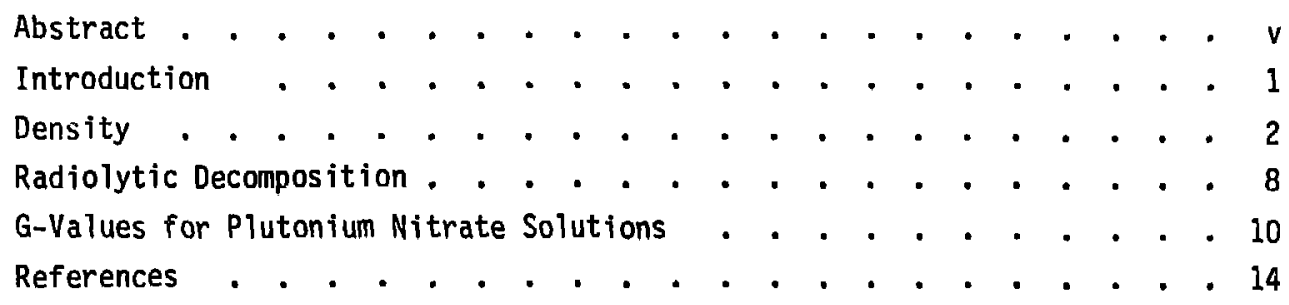




\section{ABSTRACT}

The available literature data on the density and radiolytic decomposition of plutonium nitrate solutions have been carefully reviewed to obtain correlations useful for design purposes. The density is correlated for plutonium concentrations to $480 \mathrm{~g} / \mathrm{h}$, for nitric acid concentrations to $4.3 \mathrm{~N}$, and for temperatures to $60^{\circ} \mathrm{C}$, with a standard deviation of $0.08 \%$. Radiolysis gas evolution rates from $P u(I V)$ and $P u(V I)$ solutions were examined; while the data are not as self-consistent as those for density, the correlations are useful for nitric acid concentrations to $15 \mathrm{~N}$. 


\section{INTRODUCTION}

The feasibility of using process control measurements as a part of the Material Control and Material Accounting measurements required for safeguarding nuclear material depends upon the development of proper process models, which may range from simple closure equations ${ }^{1}$ to complex dynamic estimation techniques, ${ }^{2-5}$ and upon a firm data base of physical properties and thermodynamic data for the various process streams.

While a considerable body of data exists, ${ }^{6-12}$ most of it consists of compilations made when the basic separation processes in the nuclear fuel cycle were first developed. These data were "good enough" for the job at hand but leave much to be desired when used with process models for safeguards material estimation and material loss detection. Two of the properties required for the modeling work being done at the Lawrence Livermore Laboratory are the density and radiolytic decomposition rate of plutonium nitrate solutions. The density is a basic measurement of ten used for process control and is required in specific process models for a storage tank ${ }^{2}$ and for a plutonium solution concentrator. ${ }^{4}$ The radiolysis rate is needed as part of a model to predict long-term material losses from a nitrate solution storage tank. 13

For each of the above properties, the available literature data were reviewed in detail. The quality of the data originally available was adequate for a first approximation to the radiolysis rate, but left much to be desired in the case of the density measurements. For this reason, a small number of accurate measurements were made for us at the Allied General Nuclear Services (AGNS) plant at Barnwe11, South Caroiina. These measurements are also included in this report. 


\section{DENSITY}

The Reactor Handbook ${ }^{12}$ gives, for the density of $\mathrm{Pu}\left(\mathrm{NO}_{3}\right)_{4}-\mathrm{HNO}_{3}$ solutions at $25^{\circ} \mathrm{C}$,

$$
\rho_{25}=1.0+0.031 \mathrm{M}+0.00146[\mathrm{Pu}] \text {, }
$$

where

$$
\begin{aligned}
M & =\text { nitric acid molarity }(0<M<9), \\
{[\mathrm{Pu}] } & =\text { plutonium concentration, in } \mathrm{g} / \mathrm{l}(0<[\mathrm{Pu}]<500) .
\end{aligned}
$$

This equation is nominally good to $\pm 5 \%$. There was no readily available correlation for the effect of temperature. (The plutonium nitrate storage tanks at AGNS were designed to be held at about $60^{\circ} \mathrm{C}$.) However, experts in the nuclear industry disclosed the following correlation ${ }^{*}$ :

$$
\rho_{T}=1.0125 \rho_{25}+0.000145 t-0.0005 \rho_{25}-0.0036 \text {, }
$$

where $t$ is the temperature in ${ }^{\circ} \mathrm{C}$. This equation was originally developed for $\mathrm{H}_{2} \mathrm{O}-\mathrm{UO}_{2}\left(\mathrm{NO}_{3}\right)_{2}-\mathrm{HNO}_{3}-\mathrm{NaNO}_{3}$ solutions ${ }^{7}$ and recommended for other aqueous uranium streams; its applicability and accuracy when used for $\mathrm{Pu}^{8}\left(\mathrm{NO}_{3}\right)_{4}$ solutions are not known.

The data available in the literature, ${ }^{14-17}$ together with some proprietary information made available to us by AGNS, ${ }^{+}$were examined by da Roza. ${ }^{18}$ Most of the available data were obtained by people interested in the criticality of plutonium nitrate solutions and are of unknown accuracy;

\footnotetext{
*M. Weech, General Electric Co., private communication (August 1977).

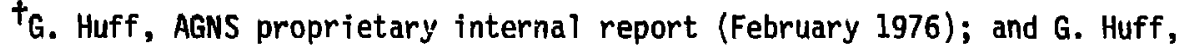
private communication (November 1976).
} 
in fact, in most of the data the temperature of the solution and the accuracy of the plutonium and free nitric acid measurements are not known. By making some assumptions about the temperatures at which some of the data were measured and by eliciting additional information from the original investigators, da Roza was able to fit the density data to within a standard error of estimate of $0.9 \%$, using

$$
\rho=P_{1}+P_{2} T+P_{3} T^{2}+P_{4} M+P_{5}[P u]+P_{6}[P u]^{2}+P_{7}[P u] T,
$$

where $T$ is in ${ }^{\circ} \mathrm{C}$. The values of the parameters $P_{1}$ through $P_{7}$ can be found in Table 1. The data used to derive this correlation extended over the following ranges:

- Plutonium concentration, [Pu]: 0 to $725 \mathrm{~g} / \ell$.

- Nitric acid concentration, M: 1.0 to $10.6 \mathrm{M}$.

- Temperature, T: 15 to $100^{\circ} \mathrm{C}$.

- Density, p: 1.0 to $2.1 \mathrm{~g} / \mathrm{ml}$.

TABLE 1. Values of parameters for density estimations. 18

\begin{tabular}{cccc}
\hline & $\begin{array}{c}\text { Concentrations } \\
\text { measured } \\
\text { at solution } \\
\text { temperature }\end{array}$ & $\begin{array}{c}\text { Concentrations } \\
\text { measured } \\
\text { at room } \\
\text { temperature }\end{array}$ & $\begin{array}{c}\text { Concentrations in } \\
\text { mole fractions }\end{array}$ \\
\hline$P_{1}$ & 1.00858 & 1.01258 & 1.09340 \\
$P_{2}$ & $-1.825 \times 10^{-4}$ & $-3.313 \times 10^{-4}$ & $-3.015 \times 10^{-3}$ \\
$P_{3}$ & $-2.787 \times 10^{-6}$ & $-2.258 \times 10^{-6}$ & $1.924 \times 10^{-5}$ \\
$P_{4}$ & $2.867 \times 10^{-2}$ & $2.857 \times 10^{-2}$ & 1.257 \\
$P_{5}$ & $1.792 \times 10^{-3}$ & $1.783 \times 10^{-3}$ & 19.15 \\
$P_{6}$ & $-5.273 \times 10^{-7}$ & $-5.006 \times 10^{-7}$ & -93.73 \\
$P_{7}$ & $-1.393 \times 10^{-6}$ & $-1.634 \times 10^{-6}$ & $-2.156 \times 10^{-2}$ \\
Standard & & & \\
error of & & & $1.94 \times 10^{-2}$ \\
estimate & $8.90 \times 10^{-3}$ & $8.63 \times 10^{-3}$ & \\
\hline
\end{tabular}


In view of the possible large, unknown systematic error in the available data and since solution density is a basic part of the measurements at a fuel cycle facility, a few high-accuracy measurements were commissioned at AGNS. ${ }^{19}$ Since their report is not generally available, the essential details of their experimental technique are summarized here.

They prepared a primary concentrated solution by dissolving $\mathrm{PuO}_{2}$ in $10 \mathrm{~N}$ nitric acid and controlled the plutonium stoichiometry by the addition of a few milligrams of $\mathrm{NaNO}_{2}$. They used aged, typical light water reactor grade plutonium having the isotopic composition given in Table 2.

TABLE 2. Isotopic composition of plutonium used by AGNS.

\begin{tabular}{lc}
\hline Isotope & Weight percent \\
\hline $238 \mathrm{Pu}$ & 0.455 \\
$239 \mathrm{Pu}$ & 70.320 \\
$240 \mathrm{Pu}$ & 22.156 \\
$241 \mathrm{Pu}$ & 4.50 \\
$242 \mathrm{Pu}$ & 2.56 \\
$241_{\mathrm{Am}}$ & 0.80 \\
\hline
\end{tabular}

The density was measured using an Anton Parr DMA-10 densitometer. The temperatures were achieved by circulating thermostatically controlled water through the remote head of the densitometer and were measured with thermistors. For calibration purposes, standard solutions of bismuth nitrate (maximum density $1.4 \mathrm{~g} / \mathrm{ml}$ ) and uranium nitrate (maximum density $1.7 \mathrm{~g} / \mathrm{ml}$ ) vere used to verify correct operation of the densitometer and to obtain a measure of instrument accuracy. The calibrations indicate that the densities are accurate to $\pm 0.04 \%$ (one sigma); replicate measurements on the plutonium solutions indicate better than $\pm 0.03 \%$ precision (one sigma). 
The chemical analysis for the free acid concentration was accomplished using an oxalate-complex titration method. Analysis of uranyl nitrate control samples indicate an accuracy of $\mathbf{0 . 7 \%}$ (one sigma) and a precision on replicate samples of $0.5 \%$ (one sigma).

The plutonium concentration was determined by converting the nitrate solution to sulfate and using controlled potential coulometry. A PAR Model 380 Controlled Potential Digital Coulometer System was used, and plutonium standards were prepared using SRM-946e plutonium metal obtained from the National Bureau of Standards.

The experimental results shown in Table 3 were fit with an equation of the form

$$
\rho=C+P_{1}[P u]+P_{2}\left[H^{+}\right]+P_{3} T+P_{4}[P u]\left[H^{+}\right]+P_{5}[P u] T+P_{6}[P u]^{2}
$$

where

$$
\begin{aligned}
\rho & =\text { density, in } \mathrm{g} / \mathrm{ml}, \\
{[\mathrm{Pu}] } & =\text { plutonium concentration, in } \mathrm{g} / \mathrm{l}, \\
{\left[\mathrm{H}^{+}\right] } & =\text {free nitric acid concentration, in } \mathrm{g} \text { moles } / \ell, \\
{[\mathrm{T}] } & =\mathrm{t}-25, \text { with } \mathrm{t}=\text { temperature in }{ }^{\circ} \mathrm{C},
\end{aligned}
$$

and the coefficients are

$$
\begin{aligned}
& C=0.99708, \\
& P_{1}=1.65625 \times 10^{-3}, \\
& P_{2}=3.2959 \times 10^{-2}, \\
& P_{3}=-5.9915 \times 10^{-4},
\end{aligned}
$$




$$
\begin{aligned}
& P_{4}=-4.8706 \times 10^{-5}, \\
& P_{4}=-1.4217 \times 10^{-6}, \\
& P_{6}=-3.418 \times 10^{-8} .
\end{aligned}
$$

TABLE 3. Results of acid-density-concentration study for plutonium nitrate solutions. Numbers in parentheses are olie sigma errors based on replicate measurements (e.g., $51.06 \pm 0.04 \mathrm{~g} / \mathrm{l}$ ).

\begin{tabular}{ccccccc}
\hline $\begin{array}{c}\text { Plutonium } \\
\text { concentration, } \\
\mathrm{g} / \ell\end{array}$ & $\begin{array}{c}\text { Acid } \\
\text { concentration, }\end{array}$ & & \multicolumn{5}{c}{$\begin{array}{c}\text { Density } \\
\mathrm{g} / \mathrm{m} \ell\end{array}$} \\
\cline { 4 - 7 } \cline { 4 - 7 } & at $25^{\circ} \mathrm{C}$ & at $35^{\circ} \mathrm{C}$ & at $45^{\circ} \mathrm{C}$ & at $60^{\circ} \mathrm{C}$ \\
\hline $51.06(0.04)$ & $2.95(0.02)$ & 1.1708 & 1.1649 & 1.1585 & 1.1481 \\
$230.80(0.41)$ & $1.47(0.01)$ & 1.4076 & 1.4004 & 1.3921 & 1.3789 \\
$235.07(0.49)$ & $3.07(0.02)$ & 1.4500 & 1.4400 & 1.4323 & 1.4171 \\
$249.45(0.45)$ & $4.27(0.03)$ & 1.4987 & 1.4888 & 1.4791 & 1.4609 \\
$477.09(0.38)$ & $2.87(0.02)$ & 1.8070 & 1.7952 & 1.7816 & 1.7632 \\
\hline
\end{tabular}

A comparison of calculated versus experimental densities is shown in Fig. 1. The standard deviation of the fit (calculated minus experimental) is $0.08 \%$, and the maximum deviation of any data point from the computed value is $0.18 \%$. 


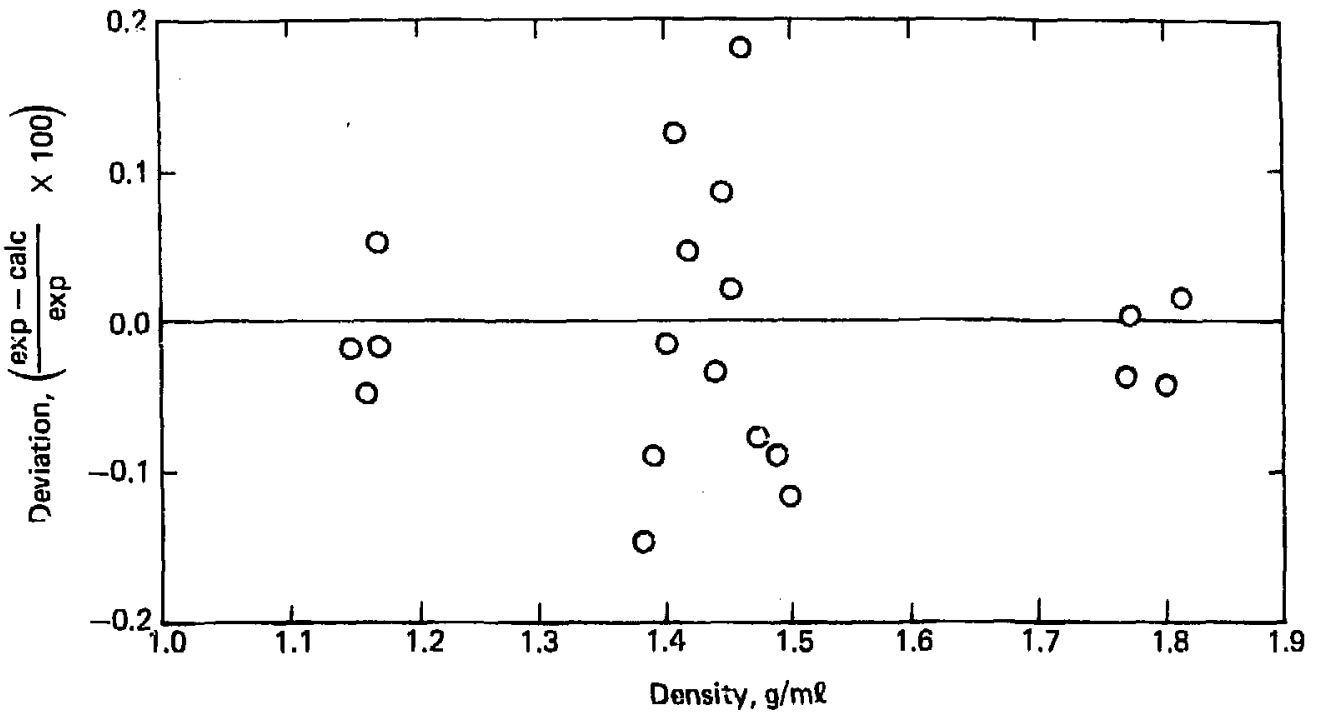

FIG. 1. Comparison of calculated versus experimental densities determined in this study. 


\section{RADIOLYTIC DECOMPOSITION}

The radiolytic decomposition of plutonium nitrate solutions is of technical interest primarily because of the volume of hydrogen gas generated. Since hydrogen forms explosive mixtures when its concentration in air exceeds $4 \%$ by volume, tanks containing solutions of radioactive materials are flushed with a continuous stream of air to dilute the hydrogen to an acceptable level. The solution of radioisotopes evaporates into this stream of air, leading to additional loss of material from the tank.

The detailed mechanisms of radiolytic decomposition are complex and not well understood. 20-22 Alpha, neutron, and gamma irradiations of nitrate solutions indicate that the main radiolysis product is nitrous $i^{23,24}$; however, we are concerned particularly with the gaseous decomposition products. The results of the varinus irradiation techniques, including the self-radiolysis of plutonium nitrate solutions do not allow the formulation of a self-consistent picture. $25-28$

The amount of gas evolved as a result of radiolytic decomposition is traditionaliy expressed in G-values, whose units are gas molecules evolved per $100 \mathrm{eV}$ deposited in the material. ${ }^{*}$ It has been found that, in the region of interest, temperature and plutonium concentration have no effect on gas evolution (G-value); however, the amounts and composition of the gas evolved from the nitrate solutions depend upon nitric acid concentration, plutonium stoichiometry, ${ }^{27,28}$ the oxygen content of the solution, ${ }^{26}$ the degree of stirring of the solution, ${ }^{28}$ and probably the extent of alpha-induced reactions in the gas phase. Most of these effects are very incompletely documented, and it is not possible to derive substantial conclusions. "When the G-value is known, the total gas evolution can be obtained from

\footnotetext{
kG-values can be expressed in other units, according to the following: $1 \frac{\text { gas molecule }}{100 \mathrm{eV}}=1.036 \times 10^{-7} \frac{\mathrm{g} \text { moles of gas }}{\mathrm{J}}=98.2 \frac{\mathrm{ft}^{3} \text { at } 60^{\circ} \mathrm{F}}{10^{6} \mathrm{Btu}}$.
} 


$$
V=G_{t} Q \text {, }
$$

where $W_{t}$ is the specific power and $Q$ is the mass of radioisotopes in solution. The total energy being deposited in the solution is equal to $W_{t} Q$. The specific power is obtained from

$$
W_{t}=0.01 \sum w_{i} P_{i} \text {, }
$$

where $W_{i}$ is the weight percent of the different isotopes in the solution and $P_{i}$ is the specific power of each isotope, obtained from Table 4.

\begin{tabular}{|c|c|c|}
\hline Isotope & Atomic weight 29 & $\begin{array}{c}\text { Specific power }\left(P_{i}\right) \text {, } \\
\mathrm{W} / \mathrm{g}^{30}\end{array}$ \\
\hline $238 \mathrm{Pu}$ & 238.0495 & 567.16 \\
\hline${ }^{239} \mathrm{Pu}$ & 239.0522 & 1.9293 \\
\hline $240 \mathrm{Pu}$ & 240.0540 & 7.098 \\
\hline${ }^{241} \mathrm{Pu}$ & (241.055) estimate & 3.390 \\
\hline $242 \mathrm{Pu}$ & 242.0587 & 0.1146 \\
\hline $241_{A m}$ & 241.0567 & 114.23 \\
\hline
\end{tabular}

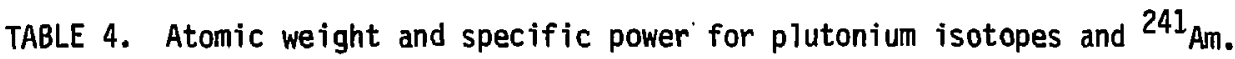


The most self-consistent set of results regarding radiolytic decomposition has been obtained by sealing a solution in a coritainer with a suitable gas space, following the rate of pressure build-up and subsequently analyzing the gas. In what follows, the effect of nitric acid and initial Pu(VI) concentrations will be discussed. (It should be noted, however, that solutions of plutonium nitrate in which plutonium has different initial oxidation states evolve, through internal oxidation-reduction reactions, to a stable Pu(IV) solution in which other oxidation states, $\mathrm{Pu}(\mathrm{III})$ or $\mathrm{Pu}(\mathrm{VI})$, are undetectable.)

Crawley $^{27}$ and Swanson and Gray ${ }^{28}$ attempited to obtain data on the effect of Pu(VI) radiolysis; however, Swanson and Gray's results were affected by air contamination and can be used only to indicate that total gas evolution is not highly dependent on temperature, but that it is enhanced by the presence of Pu(VI).

Crawley ${ }^{27}$ investigated solutions of different initial Pu(VI) content, but did not analyze his results in detail. Since he is the only investigator reporting usable results on Pu(VI) radiolysis, his raw data were reevaluated. . The energy deposition rate was obtained from his reported concentrations and isotopic ratios. His gas analysis was corrected to obtain the net radiolytic gas composition (free of residual air and helium); then, following his suggestion, his three data points were examined to see if all the oxygen could be attributed to $\mathrm{Pu}(\mathrm{VI})$ reduction. Indeed this was so, thus the average stoichiometry of the reaction appears to be

$$
\mathrm{PuO}_{2}^{+2}+2.1 \mathrm{H}^{+} \rightarrow \mathrm{Pu}^{+4}+0.475 \mathrm{O}_{2} \uparrow+1.05 \mathrm{H}_{2} \mathrm{O} \text {. }
$$

The coefficient for $0_{2}$ was obtained by linear regression on his three data points. The coefficient of determination, $r^{2}=0.990$, indicates a reasonably good fit.

The above stoichiometry is substantially different from that actually suggested by Crawley: 


$$
\mathrm{PuO}_{2}^{+2}+\mathrm{H}^{+} \rightarrow \mathrm{Pu}^{+4}+0.75 \mathrm{O}_{2}+0.5 \mathrm{H}_{2} \mathrm{O}
$$

The oxidation-reduction reaction leading to the disappearance of $\mathrm{Pu}$ (VI) appears to proceed as a zero-order reaction (i.e., with a constant reaction rate):

$$
\frac{d[P u(V I)]}{d t}=0.833 \% / \text { day }
$$

The amounts of residual gas reported by Crawley (after accounting for the oxygen as above) are anomalously low when compared with the results of Sheppard, ${ }^{26}$ Swanson and Gray, ${ }^{28}$ and Kazanjian andi Horre $11,{ }^{25}$ described below. Crawley's results were not included in the correlation of G-values.

The G-values for the total gas evolved (Fig. 2) and for the hydrogen evolved (Fig. 3) are plotted against total ritrate concentration in moles/l. There is reasonably good agreement among the three sets of data, ${ }^{25,26,28}$ which can be fit with third-degree polynomials:

$$
G=B_{0}+B_{1} M+B_{2} M^{2}+B_{3} M^{3} \text {, }
$$

where $M$ is the total nitrate ion concentration in $g$ moles/ $l$, and the values of the coefficients are:

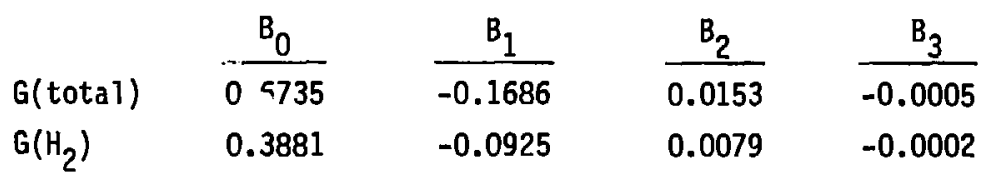

The coefficient of determination, $r^{2}$, is 0.8001 for $G($ total) and 0.9495 for $\mathrm{G}\left(\mathrm{H}_{2}\right)$. The smooth curves shown in Figs. 2 and 3 are the results of the polynomial fits. 


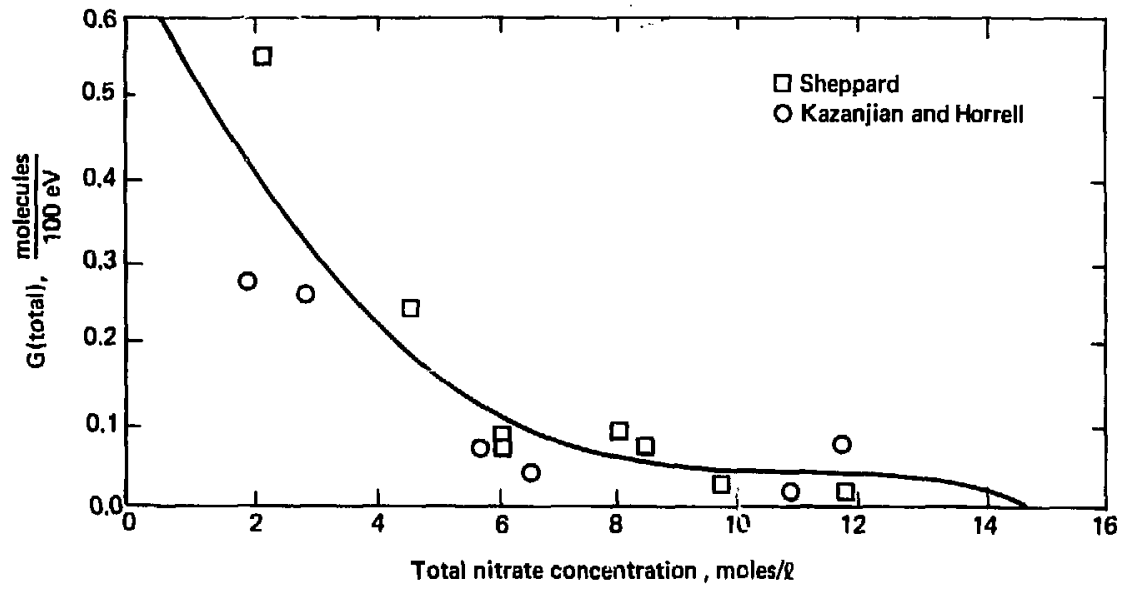

FIG. 2. G-values for total gas evolved as a function of nitrate concentration. The smooth curve is the result of a polynomial fit.

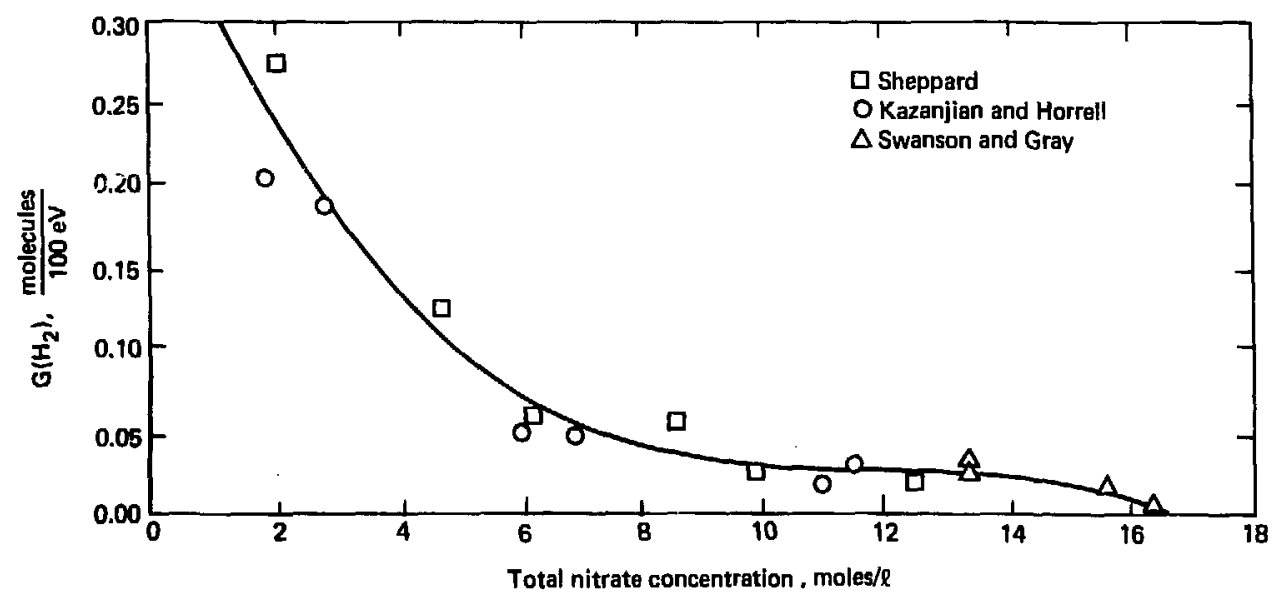

FIG. 3. G-values for $\mathrm{H}_{2}$ evolved as a function of nitrate concentration. The smooth curve is the result of a polynomial fit. 
The information given above, while typical of the data available, does not allow us to obtain a material balance in altank containing plutonium solutions; we need to examine in more detail the products of the gas analysis. Unfortunately, available information is contradictory. Nonetheless, the ratio of $\mathrm{O}_{2}$ to $\mathrm{H}_{2}$ averaged 0.51 for all experiments, with a standard deviation of 0.10 . This indicates that $G\left(\mathrm{H}_{2}\right)$ is a gooc measure of the decomposition of $\mathrm{H}_{2} \mathrm{O}$ from the solution.

The experiments for which the ratio of $\mathrm{O}_{2}$ to $\mathrm{H}_{2}$ was not close to 0.5 were generally conducted at high acid concentrations, where the total amount of gas produced was small and where $0_{2}$ production tended to be below the mean value. The exceptions are two data points recorded by Sheppard, ${ }^{26}$ where excess $\mathrm{O}_{2}$ was produced, possibly due to $\mathrm{Pu}(\mathrm{VI})$. Nitrogen and some of its oxides have also been reported in small amounts ( 0 to $21 \%$ of the hydrogen produced, average 5\%), but the information is not adequate to identify the radiolysis products of nitric acid. 


\section{REFERENCES}

1. P. W. Seabaugh, D. R. Rogers, H. A. Wolterman, F. C. Fashimi, and A. F. Cirame1la, The Controllable Unit Approach to Material Control: Application to a High Through-Put Mixed Oxide Process, Mourd Laboratory, Mound, Ohio, MLM-NUREG-2532, to be published.

2. D. R. Dunn, "Dynamic Models, Estimation and Detection Concepts for Safeguarding $\mathrm{Pu}\left(\mathrm{NO}_{3}\right)_{4}$ in Storage Tanks," נ. Inst. Nucl. Mat. Mgmt. VI (III), 509 (1977).

3. J. V. Candy, R. A. Emmert, and G. K. Patterson, Process Monitor Design for an Extraction Column: An Application of Estimation/Detection, Lawrence Livermore Laboratory, Livermore, Calif., UCID-18128 (March 1979).

4. J. V. Candy and R. B. Rozsa, On-Line Estimator/Detector for a Plutonium Nitrate Concentrator Unit, Lawrence Livermore Laboratory, Livermore, Calif., UCID-18124 (April 1979).

5. R. Emmert, G. Patterson, and J. Candy, Material Accounting in a Complex Chemical Processing Unit: An Application of Estimation/Detection, Lawrence Livermore Laboratory; Livermore, Calif., UCRL-79607 (1977); also in Proceedings, Lawrence Symposium on System and Decision Sciences (October 3, 1977), p. 40.

6. Purex Technical Manual, General Electric Hanford Atomic Products Operation, Richland, Wash., HW-3100 (Del.) (March 25, 1955).

7. R. F. Fleming, A Compilation of Physical and Chemical Properties of Materials and Streams Encountered in the Chemical Processing Department, General Electric Company, Richland, Wash. (1958).

8. A. G. Krigens, Compilation of Physical and Chemical Properties of Material and Streams Encountered in the Chemical Processing Department, At lanticRichfield Company, Richland, Wash., ARH-724 (Add.), Addendum to HW-57336 (July 24, 1968).

9. J. M. Cleveland, The Chemistry of Plutonium (Gordon and Breach Science Publishers, New York, 1970).

10. 0. J. Wick, Ed., Plutonium Handbook, Vols. I and II (Gordon and Breach Science Publishers, New York, 1967). 
11. J. T. Long, Engineering for Fuel Reprocessing (Gordon and Breach Science Publishers, New York, 1967).

12. S. M. Stoller and R. B. Richards, Reactor Handbook, Vol. II (Interscience, New York, 1961).

13. A. Maimoni, Model For Material Losses from a Plutonium Nitrate Solution Storage Tank, Lawrence Livermore Laboratory, Livermore, Calif., to be published.

14. R. C. Lloyd et al., Nucl. Sci. Engin. 50, 130 (1973).

15. E. D. Clayton, R. C. Lloyd, and W. A. Reardon, Critical Mass Experiments with Plutonium Nitrate Solutions, General Electric Hanford Atomic Products Operation, Richland, Wash., HW-SA-2432-Rev (May 23, 1962).

16. J. G. Bruna et al., Alecto-Resultats des experiences critiques homogenes realises sur le Pu239, I235 et U233, Centre d'Etudes Nucleaires de Saclay, France, CEA-R 2814 (October 1965).

17. F. Barbry et al., Etude experimentale et theorique de l'empoisonment heterogene de solution de matiere fissile par des tubes ou des anneaux en verre au borosilicate, Centre d'Etudes Nucleaires de Saclay, France, CEA-R-3931 (Decenber 1969).

18. R. da Roza, Estimation of Plutonium Concentration from Measurements of Solution Density, Temperature and Acidity, Lawrence Livermore Laboratory, Livermore, Calif., internal report (September, 1977).

19. K. L. Hofstetter, D. L. Bowers, and R. P. Kemmerlin, Measurement of Acidity and Density of Plutonium Solutions, Allied General Nuclear Services, Barnwe11, S.C., AGNS/AS-1 (June 1978); also Lawrence Livermore Laboratory, Livermore, Calif., UCRL-13905 (1978).

20. A. K. Pikaev, Pulse Radiolysis of Water and Aqueous Solutions (Indiana University Press, 1967).

21. G. Stein, Ed., Radiation Chemistry of Aqueous Systems (Weizmann Science Press of Israel, and Interscience, New York, 1968).

22. A. J. Swallow, Radiation Chemistry, (John Wiley, New York, 1973).

23. R. G. Sowden, J. Am. Chem. Soc, 79, 1263 (1957).

24. A. R. Kazanjian et al., Tr. Far. Soc. \$6, 2192 (1970).

25. A. R. Kazanjian and D. R. Horrell, Radiation Effects 13, 227 (1972).

26. J. C. Sheppard, Alpha Radiolysis of Plutonium(IV)-Nitric Acid Solutions, Battelle Pacific Northwest Laboratory, Richland, Wash., BNWL-751 (May 1968). 
27. D. T. Crawley, Pressure Buildup of Plutonium Nitrate Solutions in Sealed Shipping Containers, Atlantic-Richfield Hanford Company, Richland, Wash., ARH-1093 (July 1969).

28. J. L. Swanson and J. H. Gray, "Properties of Concentrated Plutonium Nitrate Solutions," paper presented at the Am. Nucl. Soc. meeting, Savannah, Ga. (March 1978).

29. Handbook of Chemistry and Physics (The Chemical Rubber Company, 1973), 53rd ed.

30. ANSI Standard N15.22-1975 (American National Standards Institute, Inc., 1975).

GDV/ceb

LLL: 1979/12 